
\title{
3 B Beserch Shutere \\ Experiences of Trauma Health Care Professionals When Providing Healthcare to Immigrants in Durban Public Hospitals, South Africa.
}

Rowan Madzamba ( $\sim$ rowanmadzamba@gmail.com )

University of KwaZulu Natal https://orcid.org/0000-0002-3576-8840

Kantharuben Naidoo

University of Kwazulu-Natal

Barbara Ntombi Ngwenya

University of Botswana

\section{Research}

Keywords: Migration, Trauma, health-professionals, health determinants, South Africa, immigrants

Posted Date: September 30th, 2021

DOl: https://doi.org/10.21203/rs.3.rs-923844/v1

License: (c) This work is licensed under a Creative Commons Attribution 4.0 International License.

Read Full License 


\section{Abstract}

\section{Background}

Existing research on access to health care for immigrants in South Africa has focused on access and use of services by immigrants. Focus has been on immigrants concerns around issues of citizenship acquisition and the burdening of the country's resource-constrained healthcare system. Limited empirical research has been conducted to explore health care professionals' views, daily experiences and challenges when attending to immigrant patients in South African public hospitals. This study purports to fill in this knowledge gap by capturing experiences and challenges of trauma health care professionals when providing healthcare to immigrants in Durban public hospitals, KwaZulu Natal province in South Africa.

\section{Method}

Data were collected based on a multicase qualitative study design through face-to-face in-depth structured interviews with twenty (20) trauma health care professionals from four (4) trauma centers in Durban public hospitals. Criterion based expert purposive sampling was used to recruit participants for the study. Data collected were analysed using thematic analysis.

\section{Results}

Inability of immigrant patient to converse in English or any other local language posed a major constraint for trauma medical professional health care service provision. Poor communication and culturally based differences in interpretations of sickness causality as well as desired treatment were also reported as challenges health professionals face when attending to immigrant patients. Doctors were concerned about how these barriers presented risks of prescribing wrong treatment and the possibility of patient's non-compliance especially those who cannot not speak English or any local language.

\section{Conclusion}

To health professionals' language and communication barrier, different cultural interpretation of sickness and cause of sickness is a challenge health professional are facing when attending to immigrant patients. There is need for interpreters at hospitals or for hospitals to make it compulsory for patients who do not speak native language or English to always be accompanied by an interpreter.

\section{Background}

Migration has become a prevalent practice worldwide which continues to transform the population and economy of places of origin and destination [1]. According to [2], people migrate seeking safety, shelter, and human freedom escaping hunger, incarceration, torture, and oppression [3] This therefore marks that migration is a determinant health and is unquestionably linked to trauma and major adjustment stressors. According to [4] migrant health goes beyond the traditional management of diseases among 
mobile populations and is intrinsically linked with the broader social determinants of health. Migration is thus regarded as an additional layer of social determinants of health [5]. The increased number of migrants exerts pressure on the health care system and makes new demands on health care staff [7][6][5] [4]. As such [7] report that health care professionals are faced with challenges of providing the best care to immigrant patients. Challenges health care professionals face include language barriers difficulties in arranging care for migrants without health care coverage and treatment [8]

In South Africa, the flow of immigrants from Southern African Development Community (SADC) countries and beyond has grown remarkably since the first democratic elections in 1994, [9],[10]. Statistics according to the 2011 South African national census, an estimated 2.2 million immigrants are currently living in the country. By 2020, the SADC Migration data portal shows that the number has increased to 2.9 million. However, the increasing number of immigrants in South Africa has led to widespread belief that immigrants are straining health care services resulting in medical xenophobia as reported by [11] [12].

With the number of immigrants increasing in South Africa and realising that migration exerts pressure on the health care system marks that health care professionals face[8]. However, in South Africa, the public health reasoning that supports the provision of healthcare to international migrant groups is often overlooked in favour of concerns surrounding citizenship, legitimacy, entitlement and a resourceconstrained healthcare system[13]. Most research on health care for immigrants in South Africa has focused on access and use of services by immigrants, yet there has been little empirical research exploring health care professionals' views and experiences when attending to immigrant patients. This therefore marks that experiences and challenges health care professionals in South African hospitals face when providing health care services to immigrants are yet to be documented. This study therefore seeks to cover the gap by investigating experiences and challenges health care professionals face when attending to migrant patients by interviewing Trauma health care professionals working in selected 4 Durban public hospitals namely (King Edward Hospital, Addington, Wentworth and King Dinuzulu Hospital).

\section{Methodology}

\section{Study setting}

The study was conducted in trauma units of 4 selected public hospitals, namely King Edward Hospital, Addington Hospital, Wentworth Hospital and King Dinuzulu Hospital respectively in the city of Durban province of KwaZulu Natal, South Africa. The city of Durban has 3.9 million people. The following criteria was used to select hospitals namely, first, location in high density suburbs; second, high concentration of immigrants' residents, third, easy access to health care services and last, functional trauma centers with specialist medical and nursing care which provide initial care and stabilization of traumatic experiences on patients. The study was conducted between April 2020 to July 2020. Social violence against foreigners has been witnessed in Durban leading to numerous deaths of immigrants in 2008, 2015 and 
2017 [11]. This therefore marks that the immigrants in Durban experience trauma and major adjustment stressors which may force them to seek help and treatment from closest hospitals.

\section{Description \& Justification of the design}

A multi case study design was employed for the research. The multi case study design occurs when the study being conducted contains multiple cases[14]. That is whenever the study focuses on more than one organisation but still asking the same questions, in this case all participants from 4 different selected hospitals were asked same questions. The multiple-case study design allowed the researcher to explore the phenomena under study through the use of a replication strategy. The multi case study design was chosen because the researcher sought to explore experiences of health care professionals from 4 different selected hospitals. The multi case study offered an appropriate methodology to gain requisite information from different organisations offering similar services.

\section{Study population/sample size}

About 20 Trauma health care professionals ( 5 from each hospital) working in 4 Durban public hospitals were interviewed. Expert purposive sampling was utilized to select participants. Trauma Unit managers helped identify health care professionals to interview on scheduled time. Criteria for inclusion was qualified doctor registered with the Health Professions Council of South Africa (HPSCA) as a medical doctor to practice in trauma units and; have been working at the trauma facility for more than a year. Excluded student doctors and nurses' interns. The reason for focusing on qualified doctors was because the hospitals are also training centers for student doctors and nurses who will be working as interns so for detailed information qualified doctors were considered suitable for the study.

\section{Data Collection \& Data Management}

In-depth interviews were used in the form of semi structured face to face interviews. All interviews were done in English and no pilot study was conducted. Each interview session took 30 minutes and collected data was kept in a lockup facility with access only to the researcher. Data collected was analyzed using thematic analysis. Permission to conduct the study was granted by the Biomedical Research Ethics (BREC) University of KwaZulu Natal and Permission to conduct the study in hospital was also granted by the KwaZulu Natal Department of Health. Gate keeper permissions from the hospitals selected were also sought prior to commencement of the study and right to refuse participation was respected by the researcher.

\section{Findings}

\section{Participants Demographic characteristics}

The study sample comprised of 20 health care professionals. Eight participants were female while twelve were male and all participants interviewed have been working at the facilities for more than one year. Nine of the participants were South Africans of Indian descent and eleven were Blacks. In terms of 
demographic I only managed to capture race of participants however participants refused to share their age and country of origin. All names used to identify participants in this section are pseudo names.

\section{Main themes per hospital}

Six themes emanated from the study per hospital, these themes include, treatment, lack of medical records, Language barrier, inferiority and fear in immigrant patient during treatment, harassment of Health professional by immigrant patients' Different interpretations/meanings of sickness (illness). It can be noted that trauma health care professional across all four hospitals have more or less similar experiences when providing health care to immigrants.

\section{Treatment}

All participants interviewed reported that they attend to immigrant patients more regularly in their units. They all reported that, immigrant patients present health problems that are similar to those experienced by native South Africans across the 4 hospitals. Likewise, they too are treated the same way as locals when providing care. Additionally, they do not have to pay extra money or produce extra documentation as a pre-requisite for treatment. As such attending doctors do not enquire about the immigrants' legal status in South Africa. Furthermore, the participants reported that there are no instances in which they have denied treatment to patients on the basis of their immigrant status. One of the Doctors had this to say:

We do not check the legality of a patient; we are here to treat illness which has nothing to do with legality. We literally do not have time to check whether you are a foreigner or not, we attend to the emergency and saving lives of people regardless of where they are from (Dr. Nyoka from H2).

Another also had this to say:

Though we have communication problems with some immigrants who come for treatment, however, in terms of treatment a patient is a patient we treat them just like locals, and no special treatment should be given to anyone (Dr Mhuno from H4).

and:

Our duty is to save lives and that we do it fairly regardless of where the patient is from. Administration part of who gets to be admitted or not is not our duty. To us whoever present for treatment we treat fairly. No extra documentation we need; The only documents we may need are medical records if available (Dr Gudo from H1).

\section{Language}

All participants concurred that language and communication posed as a barrier to treatment especially with patients who could not express themselves in English. One participant had this to say 
Language is always a challenge, especially to patients who cannot understand English, it becomes a challenge to understand when they try to describe their problem (Dr Gudo from H1).

Consequently, there is a risk of prescribing wrong treatment to the patient, due to poor communication and poor description of the challenge, even giving instructions to someone who does not understand English it becomes a challenge worse if they do not bring an interpreter (Dr Mhofu from H2).

Additionally,

Sometimes when attending to the patient it is difficult to try and communicate what you would want them to do due to language and communication barrier (Dr Zongororo from H3).

\section{Poor communication contributing to inferiority and fear in immigrant patient during treatment}

Some participants reported that some immigrants present a sign of inferiority and sometimes, fear. One participant had this to say:

Immigrants who cannot explain their main problem due to language barrier sometimes become so confused and end up feeling like I might give up on them, hence a sense of fear and inferiority quickly kicks in (Dr Nyoka from $\mathrm{H} 2$ )

and another participant opined that immigrants:

Lack of knowledge sometimes makes immigrants to feel inferior and fear, especially to migrants who cannot speak any local language and cannot express themselves fully in English (Dr Zvitama from H2).

\section{Harassment of Health professional by immigrant patients}

Asked if they have ever been harassed by immigrant' patients, majority said they have never been harassed by a migrant patient. One participant had this to say:

Most of them present themselves so humble and too friendly trying to create an environment to get help (Dr Nyoka from H2).

another confessed:

I have never been harassed, knowing they are immigrants, and some do not speak English well, I do not think they can afford harassing staff (Dr Tawanda from H1).

Similar sentiments were shared:

Immigrants present themselves feeling inferior looking for help, so they cannot harass staff especially when in need of help (Dr Mhuno from H4)

Only, one participant reported being harassed by immigrants had this to say: 
Some immigrants when they come for treatment are disrespectful, there a guy who once harassed me in front of patients, shouting at me. Some immigrants become so defensive, it is like they come for treatment thinking they might be denied treatment so they come prepared to defend themselves so as to be treated. Some however are rude and disrespectful (Dr Mhofu from H2).

\section{Lack of medical records.}

Inability to present medical records, especially those patients with chronic diseases was highlighted as presenting a challenge. One of the participants had this to say:

It is difficult sometimes if a person presents for treatment and has no medical records and you cannot communicate properly due to poor English (Dr Mhofu from H2).

Another participant also said

It makes it difficult if a patient has been on medication and does not have the medical record to show for it and cannot openly tell what has been happening (Dr Dongo from H2)

\section{Different interpretations/meanings of sickness [illness]}

Different cultural practices and interpretation to presenting sickness was reported as one participant points out:

I once had a couple who came for treatment, the husband literally tried to tell me how I should address or handle his wife. With so many spiritual explanations he had for the wife's sickness, he had to tell me all of it and why they delayed coming for treatment (Dr Zongororo from H3)

Another one also said

Professionalism assist me in some cases but influence of cultural practices from immigrant patients we meet if you not careful it might be difficult to treat patients (Dr Dumbu from H4)

\section{Discussion}

\section{Immigrants health seeking behaviour}

The aim of this study was to investigate experiences of trauma health care professionals when providing healthcare to immigrants in Durban public hospitals, SA. Findings of this study show that immigrants regularly visit public hospitals for treatment. This was revealed by trauma health care professionals that more often they attend to migrant patients in the hospital, marking that when there is need for treatment immigrants seek help. The study thus debunks the popular notion that immigrants do not prioritize attendance to their health needs, and that they are more concerned with resolving socio-economic and legality issues. Further in contrast [8] findings, lack of familiarity with the health care system, immigrants, 
either do not go for treatment or underuse treatment services at their disposal. In this study health care professionals reported that immigrants are aware and familiar with where to get help when they get sick.

\section{Fair treatment of immigrants in hospital.}

This study reveals that immigrants are treated the same way locals are treated in hospitals. No extra money or extra documentation to show legality before treatment are needed from immigrants as a prerequisite for receiving care. Health professionals indicated that it is not their duty to ask the legal status of their patients. The main focus is on care. They thus do not check whether immigrants are legal status in South Africa. As such no preferential treatment is thus given to any patient regardless of which part of the country they originate, whether immigrant or a native South African. All participants reported that there are no instances where an immigrant was e denied health care treatment.

\section{Challenges' when attending to immigrants}

Regarding service provision challenges, language and communication barriers emerged especially with regard to immigrants who neither speak nor understand English. The risk posed by poor communication between patient-health care provider is the probability of wrong prescription and or disease diagnosis. Misunderstanding may have undesirable consequences emanating from wrong treatment/diagnosis and failure to follow treatment instructions (at home or for those admitted for long term care).

Differences in cultural beliefs and interpretation of illness also emerged as another challenge. Some patients insist on how their relatives should be treated. Patient-doctor differences on cultural interpretation of illness poses a challenge particularly with regard to physical examinations, observation of religious and cultural taboos pertaining to the patient. It thus becomes difficult for health professionals to enforce treatment compliance control behaviours to immigrant patients when providing services. Similarly, [15] also reported that staff in emergency care units' experience difficulties in managing behaviours of immigrants due to cultural dissimilarities. The authors report that emergency care doctors feel the burden as they have the responsibility of having to decide whether or not the immigrant needs emergency care.

Preconceived treatment cultural beliefs regarding disease causality as well as treatment modalities pose as a challenge. It becomes a challenge for health professionals to coerce compliance and risk violating patients right to take or refuse treatment. [16] also reported similar finding with regard to patients' conceptualization of a given illness and the treatment options.

Lack of medical records before and after migrating to South Africa to enable the doctors to trace the medical history of the patient and prescribe appropriate medication. The challenge is exacerbated if the patient does not speak English [16] who also reported similar findings.

Immigrants were reported to harassers of health professionals [17]. This study shows the contrary. Patient's apprehension is being harassed by doctors. Patients sense of fear when seeking treatment has also been linked to poor communication due to limited language competencies. 


\section{Limitation of the study}

I could not gather any information to help categorise and distinguish characteristics of immigrant patients attended to by the doctors. The study thus does not report any details on gender, ethnicity, local/expatriates, inflow of patients and seasonal variations. This was because participants reported that such information was not important to them and may not have full detail as their primary job is to give care to every patient regardless of his demographic characteristics or country of origin hence they could not capture such information. In terms of pparticipants demographics only race, gender and number of years worked at the facility was captured, however participants were not willing to share their age and the doctor's country of origin was not asked. The study is focusing on the views of health care professionals' experiences only.

\section{Conclusion}

Though immigrants present sign of inferiority and fear when they present for treatment, health professionals treat them similarly like natives. To health professionals' language and communication barrier, different cultural interpretation of sickness and cause of sickness is a challenge health professional are facing when attending to immigrant patients. This study therefore recommends the need for intepreters for immigrants who do not speak local laguage or english.

\section{Abbreviations}

SADC: Southern African Development Community SADC

HPSCA: Health Professions Council of South Africa (HPSCA)

\section{Declarations}

\section{Ethics and consent}

Ethics approval has been obtained from the Biomedical Research Ethics (BREC) and also from KwaZulu Natal Health department (BE706/18, KZ-201904-010). Gatekeepers Permission from all 4 Hospitals (King Dinuzulu Hospital, King Edward III Hospital, Wentworth Hospital, Addington hospital) All interviews and data material were kept confidentially, and the study conducted in line with the Helsinki Declaration. Written and oral information about the project was provided to all participants, and written informed consent was obtained and securely stored.

\section{Availability of data and materials}

Anonymised transcripts are available from the corresponding author.

\section{Competing interests}


The authors declare that they have no competing interests

\section{Funding}

The study was funded by the University of KwaZulu Natal, College of Healthy Sciences, Family medicine department. The scholarship/funder has no role in designing the study, decision to publish or preparation of the manuscript.

\section{Author contributions}

Conception and design of the study: RM., Field work: RM, Data analysis: RM., Data interpretation and contextualization: RM., Drafting of the article. RM and BN., Revising of the article: BN, Approval of the final version: $\mathrm{KN}, \mathrm{BN}$

\section{Consent for publication}

Not applicable.

\section{Acknowledgments}

I would like to acknowledge Dr. Kantharuben Naidoo (Family Medicine department, University of KwaZulu Natal) for his suggestions and comments intended to further refine the manuscript and the study methodology.

I also would want to acknowledge Professor Barbara Ntombi Ngwenya (University of Botswana) for refining and editing the article

IREX funding through UASP alumni small grants program is acknowledged for providing a platform for the development of this publication.

Finally, my sincere appreciation is expressed to all the study participants for their commitment.

\section{Authors Information}

\section{Rowan Madzamba}

Rowan Madzamba is a PhD candidate in the school Family Medicine at University of KwaZulu-Natal. Rowan does research in Family medicine, public health, demography and population studies. He is an advocate of migrant health and human rights. Rowan Madzamba is the former vice president of Population Association of Southern Africa.

\section{Professor Barbara Ntombi Ngwenya}


Barbara Ntombi Ngwenya is a professor of Applied Anthropology at the multi-disciplinary Okavango Research Institute, University of Botswana, Maun campus. Professor Ngwenya has twenty years of applied research in human health(communicable diseases) and environment (wetland and savanna ecosystems) of the Okavango river basin. Professor Ngwenya is well-grounded researcher in anthropology of infectious diseases (including HIV and AIDS and Neglected Tropical Diseases - NTDS) with a solid training in systems research,patient/client-centered participatory and trans-disciplinarity. Professor Ngwenya's scholarly work focuses on communicable diseases and environment in wetland and savanna ecosystems, has over twenty years of fieldwork experience in mixed method research designs (MMRD)and successfully implemented multi-scale and multi-site research projects as $\mathrm{PI}$ and or Co-PI with collaborators in Africa, Europe, North America and Latin America with particular attention to in indigenous health systems (IHSs) and culturally sensitive documentation including navigating complex institutional relationships between traditional health practitioners (THPs) and biomedical health practitioners (BHPs) in southern Africa,and a member of the research team commissioned conduct a national audit and development of Botswana's IKS Policy and Implementation Strategy. Professor Ngwenya research interest include human health and environment, gender, poverty and access to natural resources.

\section{Dr. Kantharuben Naidoo}

Dr. Kantharuben Naidoo currently Head-Clinical Unit- Family Medicine at University of KwaZulu-Natal. Kantharuben does research in Family Practice, Law and ethics, and Primary Care. He is an advocate for womens Rights and published and Lectures on Domestic Violence and Sexual Assault including evidence collection, Childrens Rights and Child Abuse and Emergency Care Ethics. Completed PhD on Ethical Dilemmas on admission of HIV/AIDS patients to ICU HIV/AIDS.. Working on Ethics of Covid-19 and ICU.

\section{References}

1. Segal U. Globalization, migration, and ethnicity. Public Health. 2019;172:135-42.

2. Light I, Bhachu P, Karageorgis S. Migration networks and immigrant entrepreneurship. Routledge; 2017.

3. Foster RP. When immigration is trauma: Guidelines for the individual and family clinician. Am J Orthopsychiatry. 2001;71(2):153-70.

4. Mladovsky P. Migrant health in the EU. EUROHEALTH-LONDON-. 2007;13(1):9.

5. Davies AA, Basten A, Frattini C. Migration: a social determinant of the health of migrants Eurohealth. 2009;16(1):10-2.

6. Litz BT, Litz BT, Gray MJ. Emotional numbing in posttraumatic stress disorder: Current and future research directions. Australian New Zealand Journal of Psychiatry. 2002;36(2):198-204.

7. Suphanchaimat $R$, et al. Challenges in the provision of healthcare services for migrants: a systematic review through providers' lens. BMC Health Serv Res. 2015;15(1):1-14. 
8. Priebe S, et al. Good practice in health care for migrants: views and experiences of care professionals in 16 European countries. BMC Public Health. 2011;11(1):1-12.

9. Madzamba R, Economic and social interactions of immigrants with the local population: a case of Zimbabweans working in Durban CBD. 2017.

10. Crush J, Peberdy S, Criminal tendencies: Immigrants and illegality in South Africa. 2018.

11. Vanyoro KP. 'When they come, we don't send them back': counter-narratives of 'medical xenophobia'in South Africa's public health care system. Palgrave communications. 2019;5(1):1-12.

12. Crush J, Tawodzera G. Living with xenophobia: Zimbabwean informal enterprise in South Africa. Southern African Migration Programme; 2017.

13. Vearey J. Mobility, migration and generalised HIV epidemics: a focus on sub-Saharan Africa, in Handbook of Migration and Health. Edward Elgar Publishing; 2016.

14. Yin RK. Case study research: Design and methods. Vol. 5: sage; 2009.

15. Hultsjö S, Hjelm K. Immigrants in emergency care: Swedish health care staff's experiences. International nursing review. 2005;52(4):276-85.

16. Priebe $S$, et al. Good practice in mental health care for socially marginalised groups in Europe: a qualitative study of expert views in 14 countries. BMC Public Health. 2012;12(1):1-12.

17. Ozolins L-L, Hjelm K. Nurses' experiences of problematic situations with migrants in emergency care in Sweden. Clinical effectiveness in nursing. 2003;7(2):84-93. 